\title{
STUDY ON RUTTING AND SURFACE BEHAVIOUR OF URBAN FLEXIBLE PAVEMENT
}

\author{
KumKum Bhattacharya ${ }^{1}$, Sagar Deshmukh ${ }^{2}$ \\ ${ }^{I}$ M.Tech Scholar Department Of Civil Engineering, Gujarat Technological University \\ ${ }^{2}$ Chief General Manager, LEA Associates
}

\begin{abstract}
Pavement rutting is one of the peculiar and far impacting pavement distresses which being observed in flexible pavements. At present, the pavement surface at the bus shelter area appears to be challenging problem and requires maximum attention due to its severe distress, categorized as higher severity rutting. In order to ponder upon such high severity distress, some of the alternative solutions could stand as: Mastic Asphalt (MA), Use of Modified Bitumen, Stone Matrix Asphalt (SMA), White-topping, Glass Fiber Grid, Rigid Pavements and paver-blocks. Thus the overall objective of this study is to explore various alternatives of similar environments and arrive at optimum kind of alternative for Urban Flexible Pavements and also for BRTS Bus Shelters and to evaluate the damage analysis by the use of KENPAVE software of each alternative and compare the cost analysis.
\end{abstract}

Keywords: Flexible Pavement, Mastic Asphalt, Rutting, Stone Matrix Asphalt, White topping $* * *$

\section{INTRODUCTION}

Pavement rutting is the accumulation of permanent deformation in all or a portion of the layers in a pavement structure that results in a distorted pavement surface. Progression of rutting can lead to cracking and eventually complete disintegration and shoveling of the surface pavement occur which produce uncomforting for vehicle riders. Rutting is calculated as the maximum depth measured from the deepest point in the deformed wheel path to the top of the surface beside the wheel path, using a reference length of 3.0 $\mathrm{m}$. This depth is expressed in millimeter. The maximum permissible rutting depth as per IRC 37-2012 (for design traffic up to 30 msa (million standard axles) is $20 \mathrm{~mm}$.

\section{PROBLEMS AREAS}

- After the completion of phase-1, the pavement was found to breaking up fast, leading to bumpy rides for the commuters.

- $\quad$ The pavement was uneven near the bus shelters where repeated application of brakes are resulted the distress.

- The overall cost has spurred as the risen cost of bitumen is a petroleum product.

- $\quad$ Maintenance of BRTS route is also a problem because maintenance works requires the regular traffic to be stopped which creates disturbances during the transport of daily goods to the commodity and also the regular maintenance work is very inadequate.

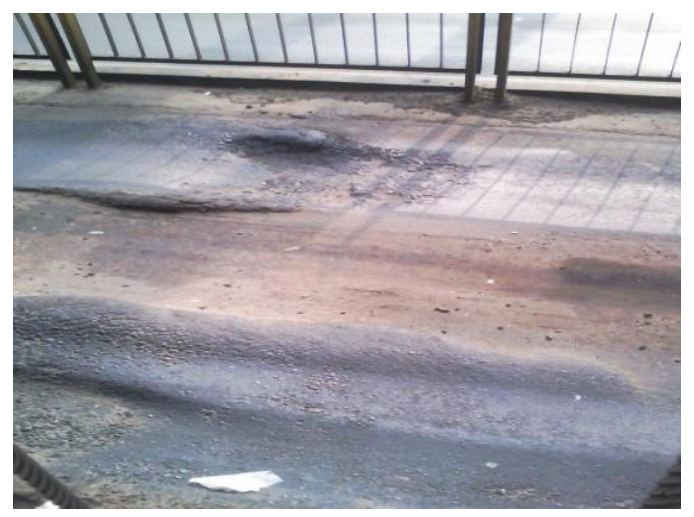

(a) Valinath chowk

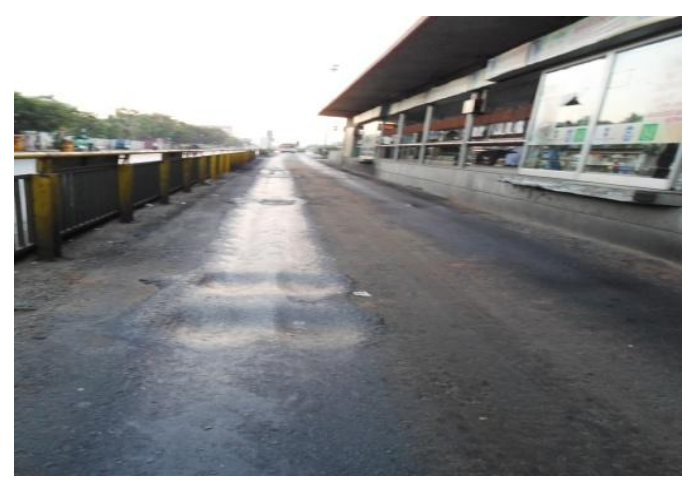

(b) Memnagar

Fig: 1 Rutting on the BRT Bus shelter [(a) \& (b)] 


\section{OBJECTIVES AND SCOPE OF THE STUDY}

- To determine the nature and extent of rutting on BRTS bus shelters.

- To evaluate typical alternate proposed solution.

- To study mixtures characterization that is susceptible to rutting and those that are not susceptible to rutting.

- Comparative analysis of other pavement with that of BRT lanes, in terms of distress extent.

\section{LITERATURE REVIEW}

Sina mirzapour (etal) in (Sept.2004): attempted to evaluate that rutting is one form of pavement distress that may influence the performance of road pavements. Geosynthetics is one type of synthetic materials which can be utilized for improving the performance of pavements against rutting.

Regarding geo synthetic reinforcement of granular material layers, aperture size, and tensile strength at small strains, junction strength and flexural rigidity of geo grids are recognized as the most important attributes in pavement sub grade stabilization. Slippage at the interface of geo textile would increase rutting and reduce confinement effect.

Kamran muzaffar khan (etal) (July, 2012): tried to evaluate and understood that pavement rutting is one of the most common and destructive pavement distresses being observed in flexible pavements. Efforts were being carried out for the improvement of mix quality and performance through the identification of mixture design parameters which relate to asphalt mix.

\section{METHODOLOGY:}

In order to understand the impact of distress the first rut depth was measured and pavement condition survey, Benkelman beam test analysis was also done along with classified volume count survey .After completion of survey the data will be analyzed for damage analysis, and economical cost analysis will also be carried out.

\section{DATA COLLECTION}

The data is collected under the following two stages:

Primary Data: - Pavement Condition Data, Rut Measurement, Benkelman Beam Deflection Data, Traffic Composition Data. Secondary Data: Material Properties, Discussion with stakeholders and various reports.

Pavement Condition Data In order to define the structural and functional needs of a roadway and specific pavement engineering design methods, evaluations were carried out on the existing pavement of project corridors. The data was collected was on two different stretch covering four bus shelters and length of $3.9 \mathrm{~km}$.

Stretch -1: Bhavsar Hostel to Shastrinagar.

Stretch -2: Jaymangal to Memnagar
Table: 1 (PAVEMENT CONDITION SURVEY)

Location: Stretch-1 Bhavsar Hostel to Shastrinagar (Appendix table 1)

From this table after pavement condition survey we had observed that raveling and patch deterioration is in high extent condition which is more shown up in the Akbarnagar Area where as other condition are not high.

Table: 2 (PAVEMENT CONDITION SURVEY)

Location: Stretch -2 Jaymangal to Memnagar (Appendix table 2)

From this table after pavement condition survey in this area we had observed that there is no high extent distress type condition.

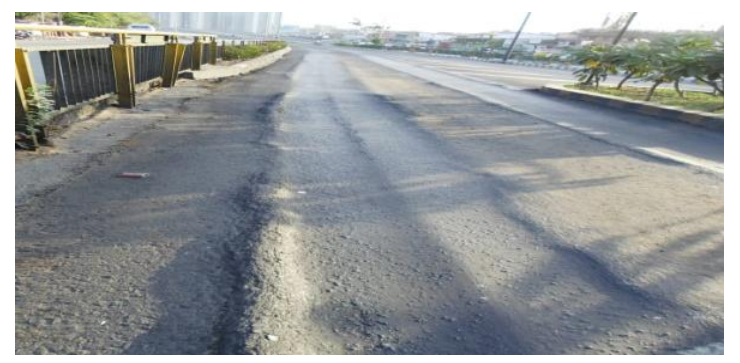

(a)

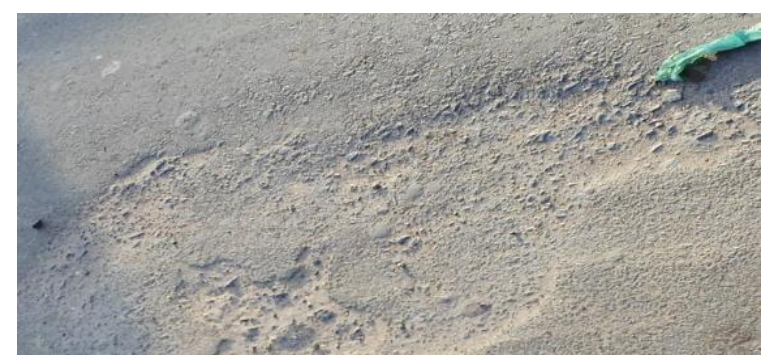

(b)

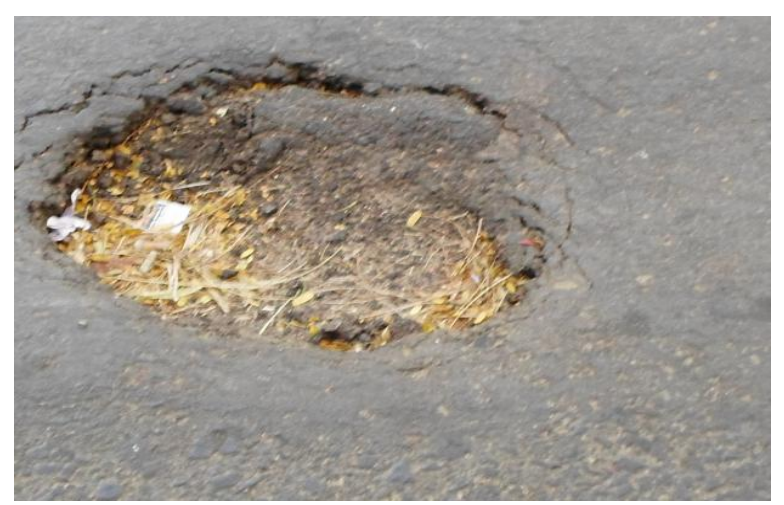

(c)

Fig-2: Distress photos of the above stretch [(a), (b), \&(c)] 
The highest value is tabulated based on the cumulative measurements

Table 3: RUT MEASUREMENT DATA: STRETCH: $1 \& 2$

\begin{tabular}{|c|c|c|c|c|c|c|}
\hline \multirow[t]{2}{*}{$\begin{array}{l}\text { SI } \\
\text { no. }\end{array}$} & \multirow[t]{2}{*}{ Bus Shelter } & \multicolumn{4}{|c|}{$\begin{array}{l}\text { Rutting Measurements(in } \\
\text { mm) }\end{array}$} & \multirow[t]{2}{*}{ Side } \\
\hline & & $\mathbf{L}$ & B & D & & \\
\hline 1. & $\begin{array}{l}\text { BHAVSAR } \\
\text { HOSTEL }\end{array}$ & 1950 & 980 & 90 & & H.S. \\
\hline 2. & $\begin{array}{l}\text { AKHBARNAGA } \\
\mathrm{R}\end{array}$ & 1490 & 790 & 65 & & H.S \\
\hline 3. & $\begin{array}{l}\text { PRAGATINAG } \\
\text { AR }\end{array}$ & 1620 & 650 & 80 & & H.S. \\
\hline 4. & $\begin{array}{l}\text { SHASTRINAGA } \\
\mathrm{R}\end{array}$ & 890 & 490 & 55 & & H.S. \\
\hline 5. & JAYMANGAL & 1340 & 745 & 30 & L.H.S & \\
\hline 6. & $\begin{array}{l}\text { SOLACROSSR } \\
\text { OAD }\end{array}$ & 1780 & 690 & 45 & R.H. & \\
\hline 7. & $\begin{array}{l}\text { VALINATH } \\
\text { CHOWK }\end{array}$ & 1580 & 560 & 85 & R.H. & \\
\hline 8. & MEMNAGAR & 1350 & 740 & 70 & L.H.s & \\
\hline
\end{tabular}

(L=length, $\mathrm{B}=$ Breadth, $\mathrm{D}=$ Depth)

\section{RUTTING DEPTH MEASUREMENT}

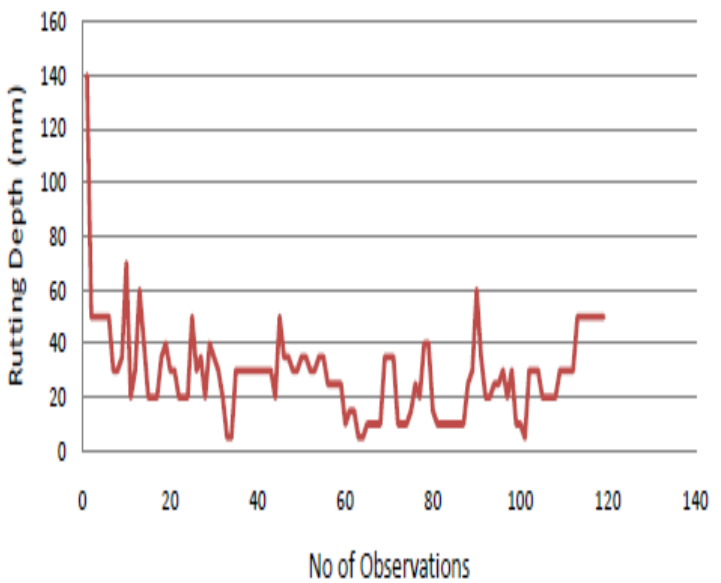

Fig: 3 Bar- Graph of Rutting Depth vs. No of observations

From the above fig. we can noticed that rutting depth decreases initially with respect to no. of observations and as no of observations progresses it varies abruptly.
Table No: 4-BENKELMAN BEAM TEST ANALYSIS

(Appendix table 3)

Name of the road: $132 \mathrm{ft}$ ring road

Section: 0-3 km

Temperature: $30^{\circ} \mathrm{c}$

Pavement: $30^{\circ} \mathrm{C}$

From this table we can observed that, The Standard and characteristics deflection measured was ( $\mathrm{mm})$ :

R.T.O-VASANA: $0.08,0.77$

VASANA-R.T.O:0.18, 1.49

TRAFFIC VOLUME COUNT IN PCU: (Shastrinagar to Bhavsar Hostel)

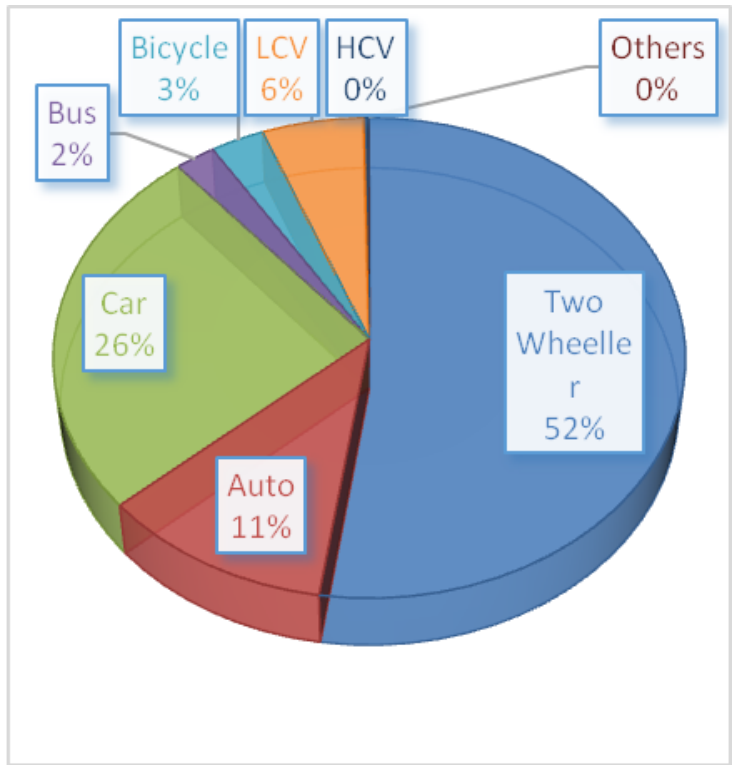

Fig4: a. Morning vehicle composition

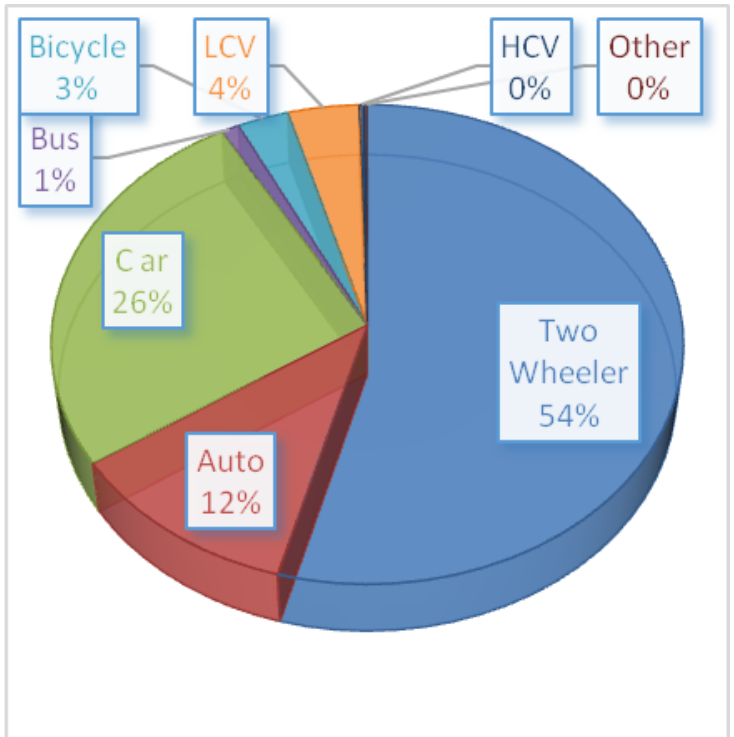

Fig4: b. Evening vehicle composition 
The above figures show the traffic composition in PCU/hr in the midblock section of peak hours on the day. The method adopted was videography method and was calculated for one hour. Here two-wheeler loads in high percentage where as bus load percentage is less in number except others.

\section{DATA ANALYSIS AND PROPOSED}

\section{ALTERNATIVES}

The rutting is generally measured in depth. As per IRC: $37-$ 2012, permissible rutting depth is $20 \mathrm{~mm}$. Looking at the case study rutting depth is found as high as $90 \mathrm{~mm}$ (at Bhavsar hostel Shelter). The average rutting depth over the entire stretch comes out to be $65 \mathrm{~mm}$. This means that the pavement has failed completely.

With respect to the above problem, suggesting the following alternatives are:

1. Stone Matrix Asphalt (SMA)

2. Flexible Pavement with Mastic Asphalt

3. Flexible Pavement reinforced with Glass Fibre Grid

4. Paver Blocks

5. Rigid Pavement (PQC)

\section{CONCLUSIONS}

From the visual observations and data collected it can be concluded that different alternative can be feasible and also economical in nature. Distress type is good in the location stretch 2 compared to stretch 1 and rutting depth though decreases initially but later on varies abruptly with the no of observations. A fundamental and research work can be carried out to improve quality of BRT system as a whole by taking various case studies. Using KENPAVE software, the evaluation of different alternatives parameters can to be adopted for the damage analysis and its susceptibility to rutting and various distresses.

\section{REFERENCES}

[1] Ahmedabad BRTS Phase-2 Detailed Project Report, Vol 1, March (2008), pp. 16-17.

[2] Ahmedabad BRTS Phase2 Detailed Project Report, Vol 2, April (2008), pp. 5, 20-21.

[3] Applicability of Bogotá's TransMilenio BRT System to the United States"NBRTI (May 2006). Retrieved (2010). Cutodio, P. (2005), "BRT planning and operation", International Forum on Bus Rapid Transit Development and Implementation, Beijing, China, 19 Oct. 2005.

[4] Zhong Wu1+ and Xingwei Chen1(June 15, 2010) "Prediction of Permanent Deformation of Pavement Base and Subgrade Materials under Accelerated Loading." ISSN 1997-1400 Int. J. Pavement Res. Technol. 4(4):231-237.

[5] By A. C. Collop,1 D. Cebon,2 and M. S. A. Hardy3 "Viscoelastic Approach to Rutting in Flexible Pavements" Vol. 121, No. I, January/February, 1995. C)ASCE. ISSN 0733-947X/95/0001-0082-0093.

[6] Kaaren Hofmann, E.i.t.and Liz hunt, and P.E. (July 1995) "Repair of Rutting by Studded Tyres"at FHWAOR-RD-96-04.

[7] Kamran Muzaffar Khan, Mumtaz Ahmed Kamal(July, 2012 ) "Rutting Based Evaluation of Asphalt Mixes”Pak. J. Engg. \& Appl. Sci. Vol. 11, July, 2012 (p. 60-65).

[8] Imran Hafeez * Mumtaz Ahmed Kamal, Muhammad Waseem Mirza, \&AyazAziz(Jan.,2012)“'Investigating the Effects of Maximum Size of Aggregate on Rutting Potential of Stone Mastic Asphalt"

[9] Srinivasa Reddy and M.Amarantha Reddy (August ,2013) "study of rutting characterisitics of bituminous binders and mixes .journal of IRC april -june 13

[10] "Determining Layer Contributions to Rutting by Surface Profile Analysis" John E. Haddock, P.E., M.ASCE1; Adam J. T. Hand, P.E., M.ASCE2.

[11] "Evaluation of rutting potential for crumb rubber modified bitumen in asphaltic mixes" S. Shankar and C.S.R.K. Prasad.

[12] "Investigation of rutting performance of asphalt mixtures containing polymer modifiers" Su“reyya Tayfur a, Halit Ozen b, Atakan Aksoy .

[13] "Improving Rutting Resistance of Pavement Structures Using Geosynthetics" - An Overview Sina Mirzapour Mounes( sept.2004). 


\section{APPENDIX}

Table 1: (PAVEMENT CONDITION SURVEY) Location: Stretch-1 Bhavsar Hostel to Shastrinagar

\begin{tabular}{|c|c|c|c|c|c|c|c|c|}
\hline \multirow[t]{2}{*}{ Sl. No. } & \multirow[t]{2}{*}{ Distress type } & \multicolumn{3}{|c|}{ Severity } & \multicolumn{3}{|c|}{ Extent } & \multirow[t]{2}{*}{ Remark } \\
\hline & & Light & Moderate & Heavy & Low & Medium & High & \\
\hline 1. & Cracking & & ------ & ------- & ------ & & ------ & Edge cracking \\
\hline 2. & Potholes & & ---- & ----- & ---- & & --- & $\begin{array}{l}100-300 \mathrm{~mm} \text { in } \\
\text { width(bowl is shape) }\end{array}$ \\
\hline 3. & Raveling & & ------ & ------ & ---- & ------ & & $\begin{array}{l}\text { More in Akbarnagar } \\
\text { area }\end{array}$ \\
\hline 4. & Rutting & & ------- & ----- & ---- & & ----- & NA \\
\hline 5. & $\begin{array}{l}\text { Patch } \\
\text { deterioration. }\end{array}$ & $-\cdots$ & & ------ & ---- & ----- & & NA \\
\hline
\end{tabular}

Table 2: (PAVEMENT CONDITION SURVEY) Location: Stretch -2 Jaymangal to Memnagar

\begin{tabular}{|c|c|c|c|c|c|c|c|c|}
\hline \multirow[t]{2}{*}{ Sl. No. } & \multirow[t]{2}{*}{ Distress type } & \multicolumn{3}{|c|}{ Severity } & \multicolumn{3}{|c|}{ Extent } & \multirow[t]{2}{*}{ Remark } \\
\hline & & Light & $\begin{array}{l}\text { Moderat } \\
\text { e }\end{array}$ & Heavy & Low & Medium & High & \\
\hline 1 & Cracking & & ----- & ----- & & ----- & ---- & $\begin{array}{l}\text { Transvers } \\
\text { e cracking } \\
(5 \%-10 \%)\end{array}$ \\
\hline 2 & Potholes & ----- & & ----- & ---- & & --- & NA \\
\hline 3 & Raveling & & ----- & ---- & & ------ & ---- & NA \\
\hline 4 & Rutting & & ----- & $-\cdots$ & & ---- & $-\cdots--$ & $\begin{array}{l}\text { Depth less } \\
\text { than } 15 \\
\text { mm }\end{array}$ \\
\hline 5 & $\begin{array}{l}\text { Patch } \\
\text { deterioration. }\end{array}$ & & ------ & $-\cdots--$ & & ------ & ----- & NA \\
\hline
\end{tabular}


Table: 3-BENKELMAN BEAM TEST ANALYSIS

Name of the road : $132 \mathrm{ft}$ ring road

Section :0-3 km

Temperature: $30^{\circ} \mathrm{C}$

Pavement $: 30^{\circ} \mathrm{C}$

\begin{tabular}{|c|c|c|c|c|c|c|c|c|c|c|c|c|c|}
\hline \multirow{2}{*}{ 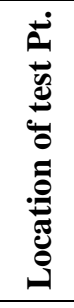 } & \multirow{2}{*}{$\begin{array}{c}\text { Offset } \\
\text { from } \\
\text { Pavem } \\
\text { ent } \\
\text { Media } \\
\text { n(m) }\end{array}$} & \multicolumn{3}{|c|}{ Dial gauge reading } & \multirow{2}{*}{ 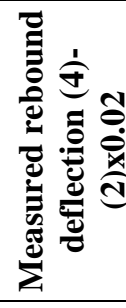 } & \multirow{2}{*}{ 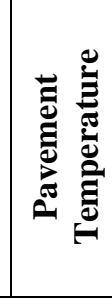 } & \multirow{2}{*}{ 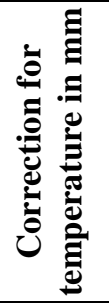 } & \multirow{2}{*}{ 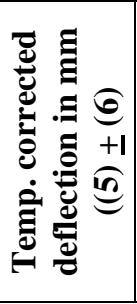 } & \multirow{2}{*}{ 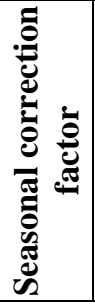 } & \multirow{2}{*}{ 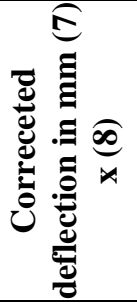 } & \multirow{2}{*}{ 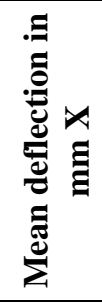 } & \multirow[b]{2}{*}{$\sum^{\stackrel{\star}{E}}$} & \multirow[b]{2}{*}{$\stackrel{\Xi}{\Sigma}$} \\
\hline & & 氮 & 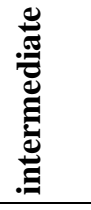 & 茎 & & & & & & & & & \\
\hline \multicolumn{14}{|c|}{ IN THE STRETCH OF 0 to 3 kms (R.T.O-VASANA) } \\
\hline 0 & 3 & 1.20 & 0.96 & 0.94 & 0.52 & 30.00 & 0.05 & 0.57 & 1.02 & 0.579 & 0.60 & 0.79 & 0.40 \\
\hline+10 & 3 & 1.78 & 1.56 & 1.55 & 0.46 & 30.00 & 0.05 & 0.51 & 1.02 & 0.518 & 0.60 & 0.79 & 0.40 \\
\hline+10 & 3 & 1.73 & 1.45 & 1.42 & 0.62 & 30.00 & 0.05 & 0.67 & 1.02 & 0.678 & 0.60 & 0.79 & 0.40 \\
\hline+10 & 3 & 3.79 & 3.56 & 3.55 & 0.48 & 30.00 & 0.05 & 0.53 & 1.02 & 0.538 & 0.60 & 0.79 & 0.40 \\
\hline+10 & 3 & 1.40 & 1.12 & 1.10 & 0.60 & 30.00 & 0.05 & 0.65 & 1.02 & 0.660 & 0.60 & 0.79 & 0.40 \\
\hline+10 & 3 & 1.20 & 0.96 & 0.95 & 0.50 & 30.00 & 0.05 & 0.55 & 1.02 & 0.558 & 0.60 & 0.79 & 0.40 \\
\hline+10 & 3 & 1.43 & 1.17 & 1.10 & 0.66 & 30.00 & 0.05 & 0.71 & 1.02 & 0.721 & 0.60 & 0.79 & 0.40 \\
\hline+10 & 3 & 1.29 & 1.00 & 0.98 & 0.62 & 30.00 & 0.05 & 0.67 & 1.02 & 0.680 & 0.60 & 0.79 & 0.40 \\
\hline+10 & 3 & 2.06 & 1.82 & 1.80 & 0.52 & 30.00 & 0.05 & 0.57 & 1.02 & 0.579 & 0.60 & 0.79 & 0.40 \\
\hline+10 & 3 & 2.22 & 2.05 & 2.02 & 0.40 & 30.00 & 0.05 & 0.45 & 1.02 & \begin{tabular}{|l|}
0.457 \\
\end{tabular} & 0.60 & 0.79 & 0.40 \\
\hline & & \multicolumn{12}{|c|}{ IN THE STRETCH OF 0 to 3 kms (VASANA-R.T.O) } \\
\hline 0 & 3 & 1.53 & 0.91 & 0.90 & 1.26 & 30.00 & 0.05 & 1.31 & 1.02 & 1.330 & 1.13 & 1.50 & 0.75 \\
\hline+10 & 3 & 1.41 & 0.96 & 0.95 & 0.92 & 30.00 & 0.05 & 0.97 & 1.02 & 0.985 & 1.13 & 1.50 & 0.75 \\
\hline+10 & 3 & 2.35 & 1.66 & 1.65 & 1.40 & 30.00 & 0.05 & 1.45 & 1.02 & 1.472 & 1.13 & 1.50 & 0.75 \\
\hline+10 & 3 & 2.70 & 2.30 & 2.29 & 0.82 & 30.00 & 0.05 & 0.87 & 1.02 & 0.883 & 1.13 & 1.50 & 0.75 \\
\hline+10 & 3 & 2.48 & 1.93 & 1.92 & 1.12 & 30.00 & 0.05 & 1.17 & 1.02 & 1.188 & 1.13 & 1.50 & 0.75 \\
\hline+10 & 3 & 2.08 & 1.59 & 1.58 & 1.00 & 30.00 & 0.05 & 1.05 & 1.02 & 1.066 & 1.13 & 1.50 & 0.75 \\
\hline+10 & 3 & 1.99 & 1.59 & 1.57 & 0.84 & 30.00 & 0.05 & 0.89 & 1.02 & 0.903 & 1.13 & 1.50 & 0.75 \\
\hline+10 & 3 & 1.12 & 0.59 & 0.58 & 1.08 & 30.00 & 0.05 & 1.13 & 1.02 & 1.147 & 1.13 & 1.50 & 0.75 \\
\hline+10 & 3 & 1.97 & 1.46 & 1.42 & 1.10 & 30.00 & 0.05 & 1.15 & 1.02 & 1.167 & 1.13 & 1.50 & 0.75 \\
\hline+10 & 3 & 1.47 & 0.96 & 0.94 & 1.06 & 30.00 & 0.05 & 1.11 & 1.02 & 1.127 & 1.13 & 1.50 & 0.75 \\
\hline
\end{tabular}

